\title{
The Role of Educational Institution in the Professional Development of the Person in the XXI Century
}

\author{
Vladimir Tsvyk \\ Department of Ethics \\ Faculty of Humanities and Social sciences \\ Peoples ' Friendship University of Russia \\ Miklukho-Maklay str., 10/2, Moscow, Russia, 117198 \\ E-mail: tsvyk_va@pfur.ru
}

\author{
Irina Tsvyk \\ Department of Philosophy \\ Moscow Aviation Institute \\ National Research University \\ Moscow, Russia \\ E-mail: tsvykirina@mail.ru
}

\begin{abstract}
The article focuses on the role of the Institute of Education in the professional development of the individual in modern society. The main stages in the professionalization of an individual are under consideration; the need to strengthen the educational component of higher education system is observed.
\end{abstract}

Keywords-education; professional development of the individual; professionalization; professional; vocational education; humanistic environment

\section{INTRODUCTION}

At the beginning of the 21st century against the backdrop of the economic and political stabilization of the Russian society, the importance of motivation of the person, who is becoming an integral part of economic and business life, is gradually growing. In the first place, the labor motivation of the individual in modern Russia comes the desire for professional development and professional growth. One of the major driving forces of social dynamics becomes professionalism as a complex, multidimensional phenomenon, which implies strengthening the social activity of the person and the increase in the extent of its responsibility for their own destiny. This improves the effectiveness of economic processes in society.

The relevance of research revolving around the problem of professional formation of the person in any business today is expanding. It is caused by the objective characteristics of the development of society at the present stage. Strategic HR policy in developed countries is aimed at training and saturation of all production links with the creative possibilities of employees. Priority is currently gaining personal development, aimed at the formation of creative thinking and initiative in professional activities.

The main principles of work put forward the need for constantly updating the knowledge and development of new professions. Among the most demanding qualities of the employee professional profile, dynamism, creativity, ability to competent estimation, social and moral responsibility are valued.
However, in professional work, not only is the individual realized but the purposeful and motivated actors involved in the system of diverse social ties and relationships are, too. The most important tool for the professional formation of this education is favored as a social institution. In modern science, education is seen as a social system actively interacting with the social environment. Its effectiveness is determined by the characteristics of the interaction of the system of education and society. It is education today that opens the way for further professional growth and personal development.

\section{PERSONALITY PROFESSIONALIZATION AND EDUCATION}

At the present stage of social development to the foreground of the problem of professional, formation comes from personal and social evolvement of a future professional as of a subject of social action. A modern professional should see their profession in combination with its broader social relationships, to know claims to be met, and to understand the content and specifics of professional activities. A modern professional should also feel confident in a circle of professional objectives and be prepared to solve them in changing social conditions. All necessary professional knowledge, skills, behaviors, values, ideals, and internal personality structure are formed in the process of professionalization of the individual.

Professionalization is a process of professional development specialization. It includes the acquisition of professional skills necessary for a successful start of professional activity, that is, acquisition of specialty. Because of their social nature, certain public bodies and social institutions carry out professionalization of individual activities. Social agents of professionalization are the family, the general educational institutions, professional educational institutions, social organizations, labor collectives, and the state as a whole.

Primary professionalization of personality begins in childhood, in the framework of the pre-school and school 
preparation. Its essence consists in the assimilation of the significant social and professional values, such as the prestige of a profession and social importance. In the works of contemporary authors, it is often emphasized that at the stage of childhood it is necessary to identify the individual and the ability to carry out initial vocational guidance. Early identification of the general direction of the natural inclinations of the individual contributes to a successful professional realization. During the pre-school period, the principal agent of professionalization is the family. The initial professional formation of the person in the family often takes place objectively. This is without special purposeful influence of parents on the child by the professional formation through the assimilation of the dominant family norms and values in the course of everyday communication. Such a direct assimilation of professional norms and values adopted in a particular family sometimes result in the formation of the so-called professional dynasties, when several generations of a family to consciously choose a certain profession, continuing their parents' business.

However, purposeful vocational education in the family is not a common norm intra life, both in Russia and in other countries. Many parents believe that the assistance in professional self-determination is the matter of schools and other educational institutions. In this, they were largely right. The most important institute of professional development of the individual in modern society is education.

The education system traditionally stands as an institution of socialization of the person as a whole. Professional formation of the person today in the 21st century serves as an essential component of socialization. As the most important agent of personality professionalization, the Institute of Education has a number of specific features.

Firstly, a distinct targeted impact: any form of education (secondary, special, professional) is characterized by a clear explication of their goals, i.e. the personality, the formation of the student's knowledge and skills, introduction to human culture, or preparation for future work. In the context of the humanistic paradigm which is based on a developmental approach among other goals of education, the disclosure of individual creative potential takes its priority.

Secondly, any education system is characterized by an orientation toward the ideal model: training and educational impact presupposes the existence of an ideal sample (expressed in the amount of skills and knowledge and personality traits), which is necessary to obtain at the output.

Thirdly, any educational institute carries the rational criteria for evaluating its activities and to be understood, as a rule, by the degree of compliance that has turned the "output" declared ideal model.

The specifics of the modern system of education is to strengthen the humanist component. In the educational institutions of the 21 st century, the dominant is shifted from education and training to personal development, the ability to form the personality, values and attitudes that meet vital needs of modern times. Thus, under education, we create conditions that can ensure the disclosure of the individual inclinations and abilities. The most important purpose of the functioning of education systems is to prepare the carriers of social functions, capable of serving modern production. In the spectrum of the leading objectives of the Institute of Education in relation to the person the following is identified:

- disclosure of the individual inclinations;

- introduction to the world and national culture through the development of systematized foundations of Arts and Sciences;

- value-conscious education and ideology development as a value orientation system, views of the world, and man's place in it;

- physical and valeological education;

- general and vocational training for employment;

- raising the individual to the level of self-upbringing and self-perception, to educational and professional activity as an art and to moral foundations and freedom.

In the context of the humanistic paradigm, education objectives of academic education, professional training in relation to the development of the person should be considered as a means of ensuring the achievement of the latter. This education system is responsible for the preparation for an independent life and professional activity of future specialists, meeting their individual educational needs.

\section{SCHOOL AS AN INSTITUTION OF PROFESSIONAL GROWTH}

Most often professionalization is referred to as special training for the future professional activity, i.e. professional training in higher education. However, the period of schooling is also important for the professional development of the individual. In secondary schools, the man not only receives the systematic and generalized knowledge necessary for the formation of a common cultural identity, but also takes on communication skills, and most importantly - the ability to work. At school, a child for the first time is included in a specific system of learning, and this inevitably gives rise to the appearance of the value of achievements. We can say that the educational situation turns a man into a genuine subject of social cognition.

Studying different academic subjects at school makes a significant contribution to the formation of the student as a potential subject of professional activity. Professional orientation includes the complex dynamic of psychological, pedagogical, and medical measures, aimed at optimizing the youth employment process in accordance with their desires, inclinations, abilities. This also takes into account the social needs carried out as early as in middle school, high school and secondary specialized schools.

With proper organization of training activities already in primary school, children develop and improve necessary qualities for future work. First of all, it is the desire and ability to work, the respect for work, public awareness of the challenges and the place of each person to their decision. 
Moreover, an important role plays not only within academic subjects directly related to the development of skills, for example, "technology", but in all general subjects developing the student's personality shaping their value orientation.

The activities of teachers in the organization of schooling should be directed, in particular, to the formation of professional consciousness of students. Professionalization of the person in the course of schooling can be considered successful if the result by the time of graduation is that the students clearly understand the connection between school and future professional activities.

Education in secondary school requires students to focus on a broad, professional orientation. In this case, the curriculum must harmoniously combine natural science subjects, which are the basis of most manufacturing processes and socio-humanitarian disciplines that form the basis of personal outlook. At the same time, teachers of general subjects, including teachers training labor (technology), trainers, and teachers of physical training should involve students into the activities in the course of which certain personal qualities, communication skills and the moral foundations of personality are formed. The inclusion of social and productive student activity contributes to the their capacity of understanding and awareness of the formation dynamics and development of their own personal qualities, and, at a certain age, professionally significant qualities.

In special schools, as a rule, there is the focus on some narrow professional direction or a particular specialty, and, therefore, more attention to relevant professional subjects and training courses are paid.

In recent years, a growing understanding of the role of the school in the process of professionalization of the person in the Russian society is noted.

One of the most important learning objectives declared the formation and development of professional consciousness, and it is the necessity of specialized high school; the creation of specialized classes with profound learning of those items that are necessary for further professional training is clearly realized. All these processes show significant and positive changes in schooling, aimed at strengthening the role of the school in the professional formation of the person.

\section{PROFESSIONAL EDUCATION IN HIGHER SCHOOL}

By its nature, the professionalization of the individual is directly related to professional education, its purpose and the result is the formation of a specialist. It is, respectively, an indicator of the successful professionalization of completing vocational education and receiving vocational training. The core of professionalization, its central component and its main stage, is vocational training and obtaining a degree in a specific university or other professional educational institutions.

The main purpose of training is to acquire specific knowledge and skills necessary for the successful implementation of a particular type of professional activity. However, obtaining a degree does not exhaust the content of this phase of the professionalization. The process of training at the university involves purposeful formation of the system of social and professional skills, deep beliefs, worldview of future specialists, which is the foundation for the development of professionalism [3. P. 142]. In addition, professional interest, not burdened by universal moral values, can cause professional narrowness; therefore, a significant component of vocational training should include moral education.

Student age is generally defined in the research literature as late adolescence personality of 17-25 years old. According to I.S. Kon, this period in the development of personality is characterized by the fact that "the leading area of activity becomes the work with the consequent differentiation of professional roles ... Education, which continues to this stage of development, is not general but special or professional, and studies at university in a certain sense can be regarded as a form of employment "[1. P. 45].

The main form of professional formation of the person at the stage of high school training is vocational education as the development of professional experience and skills to the specific type of professional work. However, the content of vocational education is not confined to the tasks of practical development of the profession. The specialist obtaining certain professional qualifications is able to go all the way to a professional only if his professional development includes, not only the acquisition of skills and abilities, but also the formation of spiritual qualities and attitudes that enable him to decide the actual personal problem of transition to active, independent, creative professional and responsible role.

The purpose of vocational education is the subject of personal development, development of professional installations, motives, attitudes, values which ensure continuous development, self-actualization, and full participation in professional life. Specifying the objectives of vocational training in high school, you can select the following tasks:

- adaptation of first-year students to the professional environment of the institution;

- creation of conditions for the further professionalization of the students; providing spiritual and moral formation;

- assisting in the social and professional selfdetermination;

- Development of professionally important human abilities and socially significant qualities;

- assistance in finding its place in the professional world after completing their education and formation of competitiveness of graduates;

- formation of professional and ethical conduct;

- the development of the objective system professional roles by individual; 
- formation of professional culture of the future expert.

In current research literature, the view that the main purpose of vocational education should be to ensure compliance with the individual qualities of the individual social requirements of the profession are also presented. At the core of this idea, a provision stating that the result of professional work (its success and satisfaction with it) depends on the degree of relatedness of individual qualities with the requirements of the profession is formulated by Talcott Parsons [9]. This provision in the framework of different theories was interpreted as conformity to the person orientation to the objective characteristics of the profession, the individual characteristics of the individual types of professions, aspirations of the individual to the objective conditions of professional activity, personal professional motivation to social requirements to the profession, typical personality to professional environment; professional alternatives to the expected success, and etc.

The new paradigm of professional education due to the requirements of the humanization of the professional relationship is based on the approval of student's active life and professional positions, creativity, motivation and selfdevelopment needs as a primary objective of the development. Today, vocational education should be focused on achieving two interrelated goals: the success of professional socialization of students in modern conditions and the human self as the subject of activity. The main content of vocational education thus is becoming the person providing socialization and professional self-development.

The major component of vocational education is vocational education as a system of socio-cultural, parenting and developmental effects in humans, aimed at the formation necessary for the profession of knowledge, skills and personal qualities. Vocational education is the process and the result of professional development and personal development, involving the mastery of pre-established knowledge, abilities and skills in specific trades and professions. At the same time, a priority of modern Russian state educational standards is the development of individual potential.

Vocational education has the following objectives:

- Creation of conditions for mastering the profession. Vocational training for each person performs two basic functions: a) a means of self-identity in the professional work; b) a means of ensuring the stability of the professional career of the individual in a market economy.

- Education of socially active members of society for creative participation in the proceedings, the responsibility for the results of their labor, the environment, etc.

- Training continuous self-learning in order to maintain the competitiveness of the individual in the labor market and a more complete disclosure of the individual abilities [7. P. 128].
Vocational education system in modern society must tackle a dual challenge: firstly, carry out the social order of society which means to train specialists needed at this point to meet public demand for labor and professional resources. Secondly, in the process of training, focus on personal development specialist, becoming its spiritual and moral image and raise the need for continuous spiritual selfdevelopment and professional self-improvement. The harmonization of these two problems and their successful execution in each vocational school is a social condition for the development of professionalism.

\section{HUMANITARIAN ASPECT OF EDUCATION}

The major component of the modernization of education is anticipating future trends in the development of society is the increased importance of the humanitarian component of higher education. For the spiritual formation and development of the individual in the course of professional education, a favorable degree of comfort on the environment is required, i.e. the humanitarian environment of high school. The structure of the humanitarian environment is a system of stable relations and relationships that affect the educational process; it is the spiritual space of the institution. The humanitarian environment provides training and the formation of spiritual and moral maturity of the students, which ultimately is implemented in the social qualities such as initiative and responsibility, the need for constant updating and enrichment of their knowledge, and the ability to make innovative decisions and actively enforce them. The presence and influence of the humanitarian environment of professional educational institution is one of the prerequisites of successful professionalization of identity and the formation of its professionalism.

Signs of humanitarian protection can be considered:

- the process of democratization in the university means the presence of special elective courses, a variety of forms of training and initiation to the research activities;

- the structure of the educational process, close to the needs of students and their future careers;

- favorable moral and psychological climate in the teaching and student groups;

- the conditions for the cultural training of students, the development of creative thinking and initiative;

- implementation of measures on social protection of members of the university staff, moral and material incentives for the most active and talented students;

- a well-developed material and technical base and the socio-cultural sphere of education.

The main system-forming factor in the process of professional formation of the person in high school is a learning process as the core of the formation of all socioprofessional and moral qualities of the future specialist. A necessary condition for the transformation of the educational process in the factor of professionalization is highlighting the personal-oriented approach to learning how to strengthen 
students' interest in obtaining professional knowledge and skills, as well as in the moral and humanistic development [8. P. 123].

The professionalization of the university is a special role that belongs to the teacher, a formative, intellectual and humanistic potential of society. The higher vocational and creative, spiritual potential of the teacher-scholar, the more favorable conditions for the development of students of spirituality and improvement of their academic and vocational training, and the more ways to self-realization.

The activities of the teacher are an integral part of the educational process of the university, providing a significant impact on its microenvironment, development and education of the person. Among other qualities necessary for successful teaching that highlight the breadth of outlook, erudition, performance, installation on creativity, awareness of the spiritual significance of its impact on the students is the need for continuous professional self-education, and competence.

Vocational education only successfully performs its function when the amount of knowledge that the teacher sends the student in the learning process becomes the intellectual culture and worldview of both those who teach as well as those who are taught. Consequently, education and science should go on to the path of harmonization, to the formation of a holistic view in the minds of teachers and their students.

Thus, vocational education in higher school is a specially organized, controlled process, in which professional development of expert, professional development of his personality structure, the gradual transition from yesterday's student to the subject of independent professional work is taken place.

\section{ROLE OF ETHICS IN VOCATIONAL EDUCATION}

An integral component of professional formation of the person in the modern world is moral education. The importance and necessity of moral education in vocational training today is fully realized. The process of training new values, complicated by fundamental nature of the status is recognized as one of the main goals of higher school. [4] There is also a growing understanding that this goal can be realized only through the harmonious combination of natural, technical, economic, and human sciences in vocational training, regardless of the particular specialization training. The need to strengthen the educational component of the higher education system determines the growth of interest and attention to ethics as to the study of morality and to practical philosophy capable today to equip the human ability properly assess its acts, harmonize the activities and interests of each person to the activities and interests of a particular collective and of the society generally.

Specificity of ethics consists in the fact that it is important and necessary in the education system, aimed not only at training and the expansion of mental horizons but also on education, improvement and spiritual growth of the individual. In modern conditions, the whole institution of culture, science, and education must be permeated by the ethical will, without which it cannot perform its main task i.e. to raise a mature, moral person, a high-level professional.

The processes of globalization in the world lead to the internationalization of higher education in Russia. A prerequisite of this is the creation of the university international humanitarian environment based on the principles of democracy, tolerance and respect for other cultures. An important part of modern higher education is also the understanding of the processes occurring in the world, the ability to analyze and moral assessment [5. P. 176]. Modern scale of the individual values should be designed taking into account the humanitarian vector which direction is fully reflected in a variety of ethical disciplines.

The professionalism of the person in the 21 st century is defined not only by its professional knowledge and skills, but also by the civil maturity of personality, psychological stability, a sense of patriotism, moral reliability [2. P. 96]. A modern professional shall not only be guided by the requirements that are applied by the scientific and professional community but should to listen carefully to the internal and external moral and psychological mechanisms of self-identity - conscience and public opinion, too.

The modern world is so dynamic, and science, technology, and human life are so interrelated that sometimes a specific solution in the professional sphere entails consequences affecting ultimately life, health and safety. Therefore, the degree of professional responsibility of the individual has been steadily increasing today. At the same time, the implementation of ethical principles in the sphere of professional activity becomes possible only if education and moral sense of duty of future experts is already seen at the stage of vocational education.

The inclusion in the curriculum of professional training of any profile of the humanities which, as a rule, raises issues of ethics, are primarily due to the currently prevailing humanistic principles in higher education. Ethics lectures are successfully delivered to students to enhance faculty qualification students from various universities and research centers in our country and abroad. But with evident ethical perspective, the importance of the state of ethics courses in the system of modern Russian education remains problematic. At the same time, the system of European education, an integral part of which is intended to become a Russian education in the framework of the Bologna process, has widespread variety of ethical discipline, especially courses of applied ethics, in particular the medical, biological, environmental, technical, computer ethics. Unfortunately, there still is little analogues, despite their obvious relevance and urgency [6. P. 135].

The introduction of an ethical component within working universities curricula is currently one of the most urgent tasks facing Russian education. Immediacy of this issue is defined as the transition to European educational standards as well as amplifying the gap between the specialized knowledge and skills obtained in the course of vocational training and the social and humanitarian knowledge contributing to the formation of moral and social position of the individual, professional and moral education. 
The value of ethics courses in modern universities is huge as in the absence of carefully developed didactic on ethical disciplines included in a learning process moral education of the people becomes more difficult. Moral education is based, inter alia, on ethical knowledge, ability to analyze human behavior from the perspective of society's moral and ethical standards.

\section{CONCLUSION}

Successful completion of the vocational education institution and obtaining the relevant specialty completes initial professional formation of a person and becomes the starting point of his entry into the world of professional relationships. In the course of a particular professional activity, further professional development of the individual and the development of its professionalism starts. At the heart of this process, there happens to be the professional activity of the person installing the continuous selfdevelopment and self-improvement, the accumulation of professional experience, and mastering the rules of professional ethics. Conversion to the skilled professional occurs in the course of professional labor. But this is possible only if in the course of professional formation of the person not only appropriate training is received, but he also lays the foundation for a humanistic outlook, trained as an active and creative person. Psychological factors of formation of professional orientation of the person are focused on improvement and work, on social mastering a wide range of norms, values and orientations, both professional and human.

In order to successfully perform the functions of the subject of the professional relationship, the individual must not only acquire knowledge, skills and abilities in terms of professional training but also master the cultural heritage of society to make it the property of their inner world. The essence of vocational education is the transmission of universal values in the learning process of each individual's special professional skill and the rules of social selfregulation. The society determines the form of professional specialization of students. The task of each individual is consciously to realize his or her socio-professional and spiritual acquisitions in society. The task of the institute, both general and vocational, is to prepare future specialist training for self-realization through its universal values, developed in the course of the historical evolution of society. Thus, the traditional understanding of vocational education as a process of formation of professionally important qualities is to be reinterpreted in the new historical conditions of the 21st century as an integral part of professionalism is the spirituality and morality.

In Russia's modern educational system still has many problems. The decisions and the success of the education system as a whole depends on how a person will be able to think independently, to acquire knowledge, to work with the information, and to work on his ability to further develop professional competence. Accordingly, he can use his intellectual skills in vocational training, and improve and develop them further. Our society needs educated, independently thinking people who are able to make justified decisions quickly.

\section{REFERENCES}

[1] Kon I.S. Psychology of a senior high school student. M.: Prosveshenie, 1982. - $191 \mathrm{p}$.

[2] Moiseenko M.V. On the formation of patriotism and spirituality in modern Russian youth // Vestnik Rossiiskogo universiteta. Seriya Filosofiya. - 2013. - №3. P. 96-103.

[3] Muhametzhanova V.S. The moral and ethical aspect of professionalism // Vestnik Rossiiskogo universiteta druzhby narodov. Seriya Filosofiya. - 2013. - №3. - P. 135-142.

[4] Savvina O.V. University Mission // Sovremennoe obrazovanie. 2012. - №2. P. 155-179.

[5] Tsvyk A.V. The moral foundations of international relations // Vestnik Rossiiskogo universiteta druzhby narodov. Seriya Filosofiya. - - 2014. - №2. - P. 176-183.

[6] Tsvyk I.V. Computer ethics and intellectual safety problems // Vestnik Rossiiskogo universiteta druzhby narodov. Seriya Filosofiya. - 2013. - №3. - P. 125-135.

[7] Tsvyk V.A. Professionalism: Experience in social and philosophical analysis. - M.: Publishing House of People's Friendship University, 2004. - 289 p.

[8] Tsvyk V.A. Professional ethics: foundations of the general theory. 3rd ed. - M., 2014. - 288 p.

[9] Parsons T. Social System and the Evolution of Action Theory. N.Y. L. 1977. 